\title{
TROPICAL SEMIÚMIDO E TROPICAL SEMISECO: OS TIPOS CLIMÁTICOS DO DOMÍNIO TROPICAL BRASILEIRO
}

\author{
Giuliano Tostes Novais $^{(a)}$, Jorge Luís Silva Brito ${ }^{(b)}$
}

(a) Instituto de Geografia, Universidade Federal de Uberlândia, giulianus@hotmail.com

(b) Instituto de Geografia, Universidade Federal de Uberlândia, jbrito@ufu.br

\section{Eixo 3: Climatologia em diferentes eixos escalares: mudanças e variabilidades}

\begin{abstract}
Resumo
As classificações climáticas são métodos empregados na identificação e caracterização de tipos climáticos, apresentando aplicação em várias áreas que dependem direta ou indiretamente das condições ambientais. O presente trabalho lança uma nova abordagem a respeito do domínio climático tropical, que é subdividido em dois tipos: um semiúmido e outro semiseco. Essa subdivisão é caracterizada pela quantidade de meses secos, queconsiste na diferença entre a precipitação pluviométrica e a evapotranpiração potencial (ETP). Dados de temperatura, precipitação e ETP de sete estações meteorológicas do Instituto Nacional de Meteorologia (INMET) serviram como base para a determinação dos tipos climáticos. Essa metodologia, juntamente com o uso de tecnologias atuais e novas fontes de dados históricos, promove um aperfeiçoamento no sistema de classificação climática utilizado no país.
\end{abstract}

Palavras chave: classificação climática, domínio climático tropical, evapotranspiração potencial

\section{Introdução}

Para oferecer uma compreensão dos diferentes climas da Terra, a Climatologia defronta-se, de maneira constante, com o desafio de converter a grande massa de dados meteorológicos e climáticos disponíveis, que diferenciam os diversos lugares da superfície da Terra, em medidas estatísticas para avaliar os aspectos significativos do clima em relação a outras variáveis espaciais. Na tentativa de resolver esse problema, os estudiosos da atmosfera aplicam o princípio da classificação para expressar os diferentes agrupamentos das características da atmosfera sobre os distintos lugares do Planeta (MENDONÇA et al, 2007).

De acordo com Barry (2013) o propósito de qualquer sistema de classificação é obter um arranjo eficiente de informações de forma simplificada e generalizada. Em termos quantitativos, as estatísticas climáticas podem descrever e delimitar os principais tipos de climas.

Considerando-se que o clima é um fenômeno dinâmico, o conhecimento dos fatores geográficos ou estatísticos, por mais completos que sejam não é suficiente para a compreensão do clima. Este não pode ser compreendido e analisado sem o concurso dos fatores dinâmicos (mecanismo atmosférico), seu principal fator genético, objeto de estudo da Meteorologia Sinótica. Todos os fatores climáticos estáticos tais como o relevo, agem sobre o clima de determinada região em interação com os sistemas regionais de circulação atmosférica (NIMER, 1989). 


\section{OS DESAFIOS DA GEOGRAFIA FÍSICA NA FRONTEIRA DO CONHECIMENTQ \\ Instituto de Geociências - Unicamp \\ Campinas - SP \\ 28 de Junho à 02 de Julho de 2017}

O território brasileiro situa-se numa zona de alta incidência solar durante o ano, com mais intensidade na estação do verão. Entre climas que vão do tórrido ao moderado, com domínios equatoriais, tropicais e subtropicais. Esses domínios climáticos são subdivididos em tipos, subtipos e até em mesoclimas e topoclimas, dependendo do geossistema onde se situa.

Área "core" do domínio morfoclimático do cerrado, paisagem transicional entre aquelas florestadas ao norte e ao leste-sul, a região central do Brasil manifesta também uma expressiva condição de transição climática (MENDONÇA et al, 2007). Através do setor oriental da região sopram, durante todo o ano, ventos geralmente de nordeste a leste do anticiclone subtropical semifixo do Atlântico Sul, responsáveis por tempo estável, em virtude de sua subsidência superior e consequente inversão de temperatura.

Essas características refletem diretamente em uma multiplicidade de tipos de tempo durante o ano, os quentes e úmidos concentrados no verão e os quentes e secos, no inverno, embora com quedas pontuais e médias de temperatura nesta última estação. Esse domínio climático é o tropical, ou conforme Mendonça (2007), tropical do Brasil Central, onde se encontram os subtipos climáticos de grande parte das Regiões Sudeste e Nordeste, e parte da Região Norte do país.

O domínio climático tropical é caracterizado pela expressiva sazonalidade, onde a estação seca pode variar de quatro a sete meses, dependendo da localização próxima de domínios mais úmidos ou mais secos. Desse modo, podemos delimitar regiões climáticas com tipos distintos. O objetivo desse trabalho é caracterizar dois tipos climáticos dentro do domínio tropical brasileiro, um semiúmido e outro semiseco.

\section{Metodologia}

Os dados foram obtidos por estações meteorológicas do Instituto Nacional de Meteorologia (INMET) durante o período de 1985 a 2015, com validade mínima de 15 anos de dados. Os meses sem dados meteorológicos completos foram descartados.

Dentre as estações analisadas foram selecionadas sete cidades piloto, sendo elas: Aragarças-GO (OMM: 83368), Areia-PB (OMM: 82696), Brasília-DF (OMM: 83377); Caratinga-MG (OMM: 83592); Pedro Afonso-TO (OMM: 82863); Teresina-PI (OMM: 82578) e Uberaba-MG (OMM: 83577). Os critérios adotados para a seleção das cidades foram: 1) Distribuição igualitária pelo território; 2) Adequação aos tipos climáticos adotados no trabalho, 3) Maior quantidade de dados mensais válidos. As outras estações que serviram para a delimitação dos tipos climáticos foram: Altamira-PA, Tauá-CE, Patos-PB, Picos-PI, Campina Grande-PB, Barbalha-CE, Bom Jesus do Piauí- 


\section{OS DESAFIOS DA GEOGRAFIA FÍSICA NA FRONTEIRA DO CONHECIMENTQ \\ Instituto de Geociências - Unicamp \\ Campinas - SP \\ 28 de Junho à 02 de Julho de 2017}

PI, Paulo Afonso-BA, Barreiras-BA, Lençóis-BA, Carinhanha-BA, Vitória da Conquista-BA, Araçuaí-MG, Nhecolândia-MS.

Nesse trabalho o domínio climático tropical, caracterizado pela expressiva sazonalidade, é dividido em dois tipos: o primeiro, com período seco de 4 a 5 meses, chamado de semiúmido; e o segundo tipo, com uma maior estação seca (6 a 7 meses), tem nomenclatura de semiseco.

A metodologia para determinação de mês seco consiste na diferença entre a precipitação pluviométrica e a evapotranpiração potencial (ETP). Se a precipitação for menor que a ETP, o mês é seco. Para o cálculo da ETP foi utilizada a planilha de balanço hídrico normal elaborada por Sentelhas et al (1998), com método de Thorntwaite\&Mather (1955), tendo a latitude e a temperatura média como parâmetros meteorológicos.

Em todo o domínio climático tropical a temperatura média do mês mais frio é superior a $18^{\circ} \mathrm{C}$, seguindo a proposta de Köppen (1936) e Nimer (1972) para climas quentes ou megatérmicos.

Serviu de base para elaboração do mapa das subdivisões do domínio climático tropical brasileiro, o mapa físico, político e rodoviário do Brasil elaborado por Novais (2012), que é um mapa hipsométrico com 30 classes de altitude que utiliza dados obtidos por imagens SRTM (WEBER et al, 2004), e também o mapa de Climas do Brasil, elaborado sobre a classificação climática de Nimer (1972).

Os valores de temperatura média influenciam diretamente no cálculo da ETP. De acordo com Mendonça (2007), o ar apresenta uma relação de resfriamento com a altitude na ordem de $0,6^{\circ} \mathrm{C}$ a cada 100 metros de elevação. Em alguns locais, o mapa hipsométrico auxiliou na delimitação dos tipos climáticos a partir de suas classes de altitude, que fazem a temperatura média ser mais baixa, e consequentemente uma ETP menor, diminuindo a quantidade de meses secos. Somente a interpolação dos dados no mapa não delimitaria essas regiões.

Foi feita um interpolação espacial dos dados das estações com o algoritmo Spline. Esse tipo de interpolação foi escolhido por conseguir estimar valores que estavam abaixo do mínimo e acima dos valores máximos encontrados na amostra (que são os dados das estações que não foram selecionadas como piloto). Essa interpolação virtualmente garante uma superfície mais suave, incorporando um modelo curvilíneo como parte do cálculo.

Esse material cartográfico na verdade é um esboço e pode ser refinado com maior quantidade de dados e em programas de geoprocessamento como o QGis.

\section{Resultados}




\section{OS DESAFIOS DA GEOGRAFIA FÍSICA NA FRONTEIRA DO CONHECIMENTQ \\ Instituto de Geociências - Unicamp \\ Campinas - SP \\ 28 de Junho à 02 de Julho de 2017}

As sete cidades utilizadas foram analisadas e adequadas aos dois tipos climáticos (semiúmido e semiseco). Os dados de cada estação meteorológica são apresentados a seguir:

\subsection{Aragarças-GO}

Situada a 345 metros de altitude numa planície às margens do rio Araguaia, a cidade de Aragarças registra temperaturas elevadas durante todo o ano. Na análise do período que vai de 1985 a 2015 o mês mais quente foi outubro com média de $28,2^{\circ} \mathrm{C}$. Já o mês com maior volume médio de chuva foi janeiro com $308 \mathrm{~mm}$. A estação úmida acontece de novembro a março (Tabela I).

A evapotranspiração potencial foi maior que a precipitação pluviométrica de abril a outubro, e de acordo com a metodologia utilizada, Aragarças possui sete meses secos, portanto é classificada como tipo tropical semiseco.

Tabela I - Dados climatológicos da estação de Aragarças-GO entre 1985 e 2015.

\begin{tabular}{|c|c|c|c|c|}
\hline & $\begin{array}{l}\text { Temperatura } \\
\text { Média (TM): } \\
{ }^{\circ} \mathrm{C}\end{array}$ & $\begin{array}{l}\text { Precipitação } \\
\text { Pluviométrica } \\
\text { (P): mm }\end{array}$ & $\begin{array}{c}\text { Evapotranspiração } \\
\text { Potencial (ETP): } \\
\text { mm }\end{array}$ & $\begin{array}{c}\text { Mês seco } \\
(\text { P-ETP })<0\end{array}$ \\
\hline Janeiro & 26.0 & 308.8 & 145.7 & \\
\hline Fevereiro & 26.1 & 208.6 & 130.1 & \\
\hline Março & 26.1 & 219.7 & 139.8 & \\
\hline Abril & 26.3 & 80.3 & 131.4 & $*$ \\
\hline Maio & 24.6 & 21.4 & 114.9 & $*$ \\
\hline Junho & 23.3 & 9.7 & 97.8 & $*$ \\
\hline Julho & 23.3 & 6.3 & 100.2 & $*$ \\
\hline Agosto & 25.4 & 10.0 & 121.0 & $*$ \\
\hline Setembro & 27.9 & 36.1 & 146.3 & $*$ \\
\hline Outubro & 28.2 & 113.7 & 160.6 & $*$ \\
\hline Novembro & 26.9 & 182.2 & 146.4 & \\
\hline Dezembro & 26.3 & 257.5 & 148.1 & \\
\hline
\end{tabular}

\subsection{Areia-PB}

Areia é uma cidade na encosta oriental da serra da Borborema, na Paraíba, a 574 metros de altitude. As temperaturas caem abaixo de $20^{\circ} \mathrm{C}$ no mês de julho. Durante o período de 1985 a 2015 os meses mais quentes foram fevereiro e março com média de $23,7^{\circ} \mathrm{C}$. O mês de julho foi o de maior valor na precipitação pluviométrica com $203 \mathrm{~mm}$. A estação úmida, diferente da maior parte do país, acontece de fevereiro a agosto (Tabela II).

A evapotranspiração potencial foi maior que a precipitação de setembro a janeiro, e de acordo com a metodologia utilizada, Areia possui cinco meses secos, portanto é classificada como tipo tropical semiúmido.

Tabela II - Dados climatológicos da estação de Areia-PB entre 1986 e 2015. 


\begin{tabular}{|c|c|c|c|c|}
\hline & $\begin{array}{l}\text { Temperatura } \\
\text { Média (TM): } \\
{ }^{\circ} \mathbf{C}\end{array}$ & $\begin{array}{l}\text { Precipitação } \\
\text { Pluviométrica } \\
\text { (P): mm }\end{array}$ & $\begin{array}{c}\text { Evapotranspiração } \\
\text { Potencial (ETP): } \\
\text { mm }\end{array}$ & $\begin{array}{c}\text { Mês seco } \\
(\text { P-ETP })<0\end{array}$ \\
\hline Janeiro & 23.5 & 83.4 & 114.1 & $*$ \\
\hline Fevereiro & 23.7 & 105.1 & 103.9 & \\
\hline Março & 23.7 & 127.6 & 114.0 & \\
\hline Abril & 23.5 & 137.8 & 106.2 & \\
\hline Maio & 22.7 & 173.8 & 100.9 & \\
\hline Junho & 21.3 & 203.1 & 85.8 & \\
\hline Julho & 19.5 & 186.0 & 74.0 & \\
\hline Agosto & 20.6 & 127.8 & 83.2 & \\
\hline Setembro & 21.4 & 55.9 & 88.0 & $*$ \\
\hline Outubro & 22.4 & 24.9 & 101.5 & $*$ \\
\hline Novembro & 23.0 & 29.5 & 105.3 & $*$ \\
\hline Dezembro & 23.5 & 40.1 & 114.0 & $*$ \\
\hline
\end{tabular}

\subsection{Brasília-DF}

Localizada no planalto Central, Brasília está a 1.160 metros de altitude. As temperaturas médias mensais nunca ultrapassam $23^{\circ} \mathrm{C}$. O mês mais quente analisado no período (1985-2015) foi outubro com média de $22,6^{\circ} \mathrm{C}$. Os meses de junho e julho foram os mais frios com $19,1^{\circ} \mathrm{C}$. A maior precipitação pluviométrica média acontece em dezembro com $249 \mathrm{~mm}$. A estação úmida vai de outubro a abril (Tabela III).

A evapotranspiração potencial foi maior que a precipitação de maio a setembro, e de acordo com a metodologia utilizada, Brasília possui cinco meses secos e é classificada como tipo tropical semiúmido.

Tabela III - Dados climatológicos da estação de Brasília-DF entre 1985 e 2015.

\begin{tabular}{|c|c|c|c|c|}
\hline & $\begin{array}{c}\text { Temperatura } \\
\text { Média (TM): } \\
{ }^{\circ} \mathbf{C}\end{array}$ & $\begin{array}{c}\text { Precipitação } \\
\text { Pluviométrica } \\
(\mathbf{P}): \text { mm }\end{array}$ & $\begin{array}{c}\text { Evapotranspiração } \\
\text { Potencial (ETP): } \\
\text { mm }\end{array}$ & $\begin{array}{c}\text { Mês seco } \\
(\text { P-ETP) }<0\end{array}$ \\
\hline Janeiro & 21.7 & 205.7 & 99.8 & \\
\hline Fevereiro & 21.8 & 183.7 & 89.3 & \\
\hline Março & 21.6 & 215.9 & 94.7 & \\
\hline Abril & 21.5 & 137.6 & $\mathbf{8 6 . 8}$ & \\
\hline Maio & 20.2 & 28.1 & 76.4 & $*$ \\
\hline & Temperatura & Precipitação & Evapotranspiração & Mês seco \\
\hline Junho & 19.1 & 4.5 & 63.8 & $*$ \\
\hline Julho & 19.1 & 6.0 & 66.1 & $*$ \\
\hline Agosto & 20.7 & 19.9 & 79.5 & $*$ \\
\hline Setembro & 22.5 & 44.6 & 94.2 & $*$ \\
\hline Outubro & 22.6 & 148.7 & 102.9 & \\
\hline Novembro & 21.6 & 240.5 & 93.2 & \\
\hline
\end{tabular}




\begin{tabular}{|l|l|l|l|l|}
\hline Dezembro & 21.5 & 249.7 & 97.5 & \\
\hline
\end{tabular}

\subsection{Caratinga-MG}

A cidade de Caratinga fica situada aos pés da Pedra de Itaúna, no leste de Minas Gerais, a uma altitude de 600 metros. O mês de fevereiro apresentou o maior valor de temperatura média durante o ano com $24,1^{\circ} \mathrm{C}$. O mês de julho foi o de menor temperatura média com $18,3^{\circ} \mathrm{C}$. O maior volume de chuva é esperado em dezembro com média de $249,5 \mathrm{~mm}$. A estação úmida vai de novembro a março (Tabela IV).

A evapotranspiração potencial foi maior que a precipitação de abril a outubro, e de acordo com a metodologia utilizada, Caratinga possui sete meses secos e é classificada como tipo tropical semiseco.

Tabela IV - Dados climatológicos da estação de Caratinga-MG entre 1986 e 2015.

\begin{tabular}{|c|c|c|c|c|}
\hline & $\begin{array}{c}\text { Temperatura } \\
\text { Média (TM): } \\
{ }^{\circ} \mathbf{C}\end{array}$ & $\begin{array}{c}\text { Precipitação } \\
\text { Pluviométrica } \\
(\mathbf{P}): \mathbf{m m}\end{array}$ & $\begin{array}{c}\text { Evapotranspiração } \\
\text { Potencial (ETP): } \\
\text { mm }\end{array}$ & $\begin{array}{c}\text { Mês seco } \\
\text { (P-ETP) }<0\end{array}$ \\
\hline Janeiro & 23.8 & 201.6 & 124.9 & \\
\hline Fevereiro & 24.1 & 115.1 & 113.1 & \\
\hline Março & 23.6 & 134.9 & 115.6 & $*$ \\
\hline Abril & 22.2 & 60.5 & 94.6 & $*$ \\
\hline Maio & 19.6 & 32.5 & 73.0 & $*$ \\
\hline Junho & 18.4 & 11.8 & 60.3 & $*$ \\
\hline Julho & 18.3 & 7.2 & 61.3 & $*$ \\
\hline Agosto & 19.4 & 15.6 & 70.9 & $*$ \\
\hline Setembro & 21.2 & 46.5 & 85.1 & $*$ \\
\hline Outubro & 22.5 & 85.6 & 103.7 & \\
\hline Novembro & 22.8 & 208.0 & 107.8 & \\
\hline Dezembro & 22.5 & 249.5 & 111.0 & \\
\hline
\end{tabular}

\subsection{Pedro Afonso-TO}

Na confluência do rio do Sono com o rio Tocantins encontra-se Pedro Afonso, a 187 metros de altitude. Registram-se temperaturas acima de $25^{\circ} \mathrm{C}$ em todos os meses do ano. Durante o período de 1985 a 2015 o mês mais quente foi setembro com média de $28,1^{\circ} \mathrm{C}$. O mês de janeiro foi o de maior acumulado médio de chuva $285 \mathrm{~mm}$. O período chuvoso vai de outubro a abril (Tabela V).

A evapotranspiração potencial foi maior que a precipitação de maio a setembro, e de acordo com a metodologia utilizada, Pedro Afonso possui cinco meses secos e é classificada como tipo tropical semiúmido.

Tabela V - Dados climatológicos da estação de Pedro Afonso-TO entre 1985 e 2015. 


\begin{tabular}{|c|c|c|c|c|}
\hline & $\begin{array}{l}\text { Temperatura } \\
\text { Média (TM): } \\
{ }^{\circ} \mathbf{C}\end{array}$ & $\begin{array}{l}\text { Precipitação } \\
\text { Pluviométrica } \\
\text { (P): mm }\end{array}$ & $\begin{array}{c}\text { Evapotranspiração } \\
\text { Potencial (ETP): } \\
\text { mm }\end{array}$ & $\begin{array}{c}\text { Mês seco } \\
(\text { P-ETP)<0 }\end{array}$ \\
\hline Janeiro & 25.9 & 285.4 & 139.8 & \\
\hline Fevereiro & 25.9 & 236.1 & 124.6 & \\
\hline Março & 26.0 & 269.0 & 137.3 & \\
\hline Abril & 26.5 & 184.6 & 134.5 & \\
\hline Maio & 26.6 & 69.2 & 137.1 & $*$ \\
\hline Junho & 25.8 & 4.1 & 123.2 & $*$ \\
\hline Julho & 25.7 & 3.8 & 126.2 & $*$ \\
\hline Agosto & 26.8 & 8.3 & 138.7 & $*$ \\
\hline Setembro & 28.1 & 42.9 & 149.5 & $*$ \\
\hline Outubro & 27.4 & 151.2 & 150.4 & \\
\hline Novembro & 26.6 & 234.7 & 140.3 & \\
\hline Dezembro & 26.2 & 246.9 & 142.3 & \\
\hline
\end{tabular}

\subsection{Teresina-PI}

Teresina, a capital do estado do Piauí, fica na margem direita do rio Parnaíba, a uma altitude de 74 metros. É a estação meteorológica mais quente e mais baixa de todas analisadas. O mês de outubro é o de maior valor térmico médio com $29,7^{\circ} \mathrm{C}$ (1985-2015). Março registrou a maior precipitação pluviométrica média com $287 \mathrm{~mm}$. A estação úmida, também diferente da maior parte do país, acontece de janeiro a maio, meses com influência da Zona de Convergência Intertropical (Tabela VI).

A evapotranspiração potencial foi maior que a precipitação de junho a dezembro, e de acordo com a metodologia utilizada, Teresina possui sete meses secos (com tendência de oito meses, ou seja, quase de clima tropical seco) e é classificada como tipo tropical semiseco.

Tabela VI - Dados climatológicos da estação de Teresina-PI entre 1993 e 2015.

\begin{tabular}{|c|c|c|c|c|}
\hline & $\begin{array}{c}\text { Temperatura } \\
\text { Média (TM): } \\
{ }^{\circ} \mathbf{C}\end{array}$ & $\begin{array}{c}\text { Precipitação } \\
\text { Pluviométrica } \\
(\mathbf{P}): \text { mm }\end{array}$ & $\begin{array}{c}\text { Evapotranspiração } \\
\text { Potencial (ETP): } \\
\text { mm }\end{array}$ & $\begin{array}{c}\text { Mês seco } \\
(\text { P-ETP) }<0\end{array}$ \\
\hline Janeiro & 23.8 & 201.1 & 116.1 & \\
\hline Fevereiro & 26.6 & 232.3 & 129.2 & \\
\hline Março & 24.9 & 287.1 & 124.6 & \\
\hline Abril & 26.5 & 266.6 & 135.4 & \\
\hline Maio & 25.1 & 125.0 & 123.5 & $*$ \\
\hline Junho & 26.5 & 18.0 & 132.4 & $*$ \\
\hline Julho & 26.7 & 9.6 & 138.5 & $*$ \\
\hline Agosto & 27.6 & 5.4 & 149 & $*$ \\
\hline Setembro & 28.9 & 9.9 & 159.1 & $*$ \\
\hline Outubro & 29.7 & 35.2 & 175.4 & $*$ \\
\hline Novembro & 27.7 & 44.4 & 149.6 & $*$ \\
\hline Dezembro & 25.1 & 92.9 & 129.1 & $*$ \\
\hline
\end{tabular}




\subsection{Uberaba-MG}

Uberaba, localizada no vale do rio Grande, é uma das principais cidades do Triângulo Mineiro, e fica a uma altitude de 737 metros. As temperaturas caem abaixo de $20^{\circ} \mathrm{Cde}$ maio a julho. Durante o período de 1985 a 2015 o mês mais quente foi outubro com média de $24,0^{\circ} \mathrm{C}$. O mês de janeiro é o de maior valor na precipitação pluviométrica com $327 \mathrm{~mm}$. A estação úmida vai de outubro a abril (Tabela VII).

A evapotranspiração potencial foi maior que a precipitação de maio a setembro, e de acordo com a metodologia utilizada, Uberaba possui cinco meses secos e é classificada como tipo tropical semiúmido.

Tabela VII - Dados climatológicos da estação de Uberaba-MG entre 1989 e 2015.

\begin{tabular}{|l|r|r|r|c|}
\hline & $\begin{array}{c}\text { Temperatura } \\
\text { Média (TM): } \\
{ }^{\circ} \mathrm{C}\end{array}$ & $\begin{array}{c}\text { Precipitação } \\
\text { Pluviométrica } \\
(\mathrm{P}): \mathrm{mm}\end{array}$ & $\begin{array}{c}\text { Evapotranspiração } \\
\text { Potencial (ETP): mm }\end{array}$ & $\begin{array}{c}\text { Mês seco } \\
(\text { P-ETP) }<0\end{array}$ \\
\hline Janeiro & 23.7 & 327.0 & 123.5 & \\
\hline Fevereiro & 23.8 & 230.7 & 109.8 & \\
\hline Março & 23.5 & 240.4 & 114.2 & \\
\hline Abril & 22.6 & 99.6 & 97.6 & \\
\hline Maio & 19.8 & 46.3 & 74.3 & $*$ \\
\hline Junho & 18.9 & 17.4 & 63.3 & $*$ \\
\hline Julho & 19.0 & 11.9 & 65.9 & $*$ \\
\hline Agosto & 21.0 & 17.2 & 82.2 & $*$ \\
\hline Setembro & 23.0 & 52.9 & 99.3 & $*$ \\
\hline Outubro & 24.0 & 133.3 & 117.7 & \\
\hline & 23.7 & 191.4 & Evapotranspiração & Mês seco \\
\hline Novembro & 23.7 & 278.3 & 116.2 & \\
\hline Dezembro & & & 123.5 & \\
\hline
\end{tabular}

A partir dos dados das estações do INMET espalhadas por toda a área e pegando como modelo as tabelas analisadas acima, foi elaborado um "mapa-esboço" do domínio climático tropical em território brasileiro, subdividido em dois tipos, semiúmido e semiseco (Figura 1). 


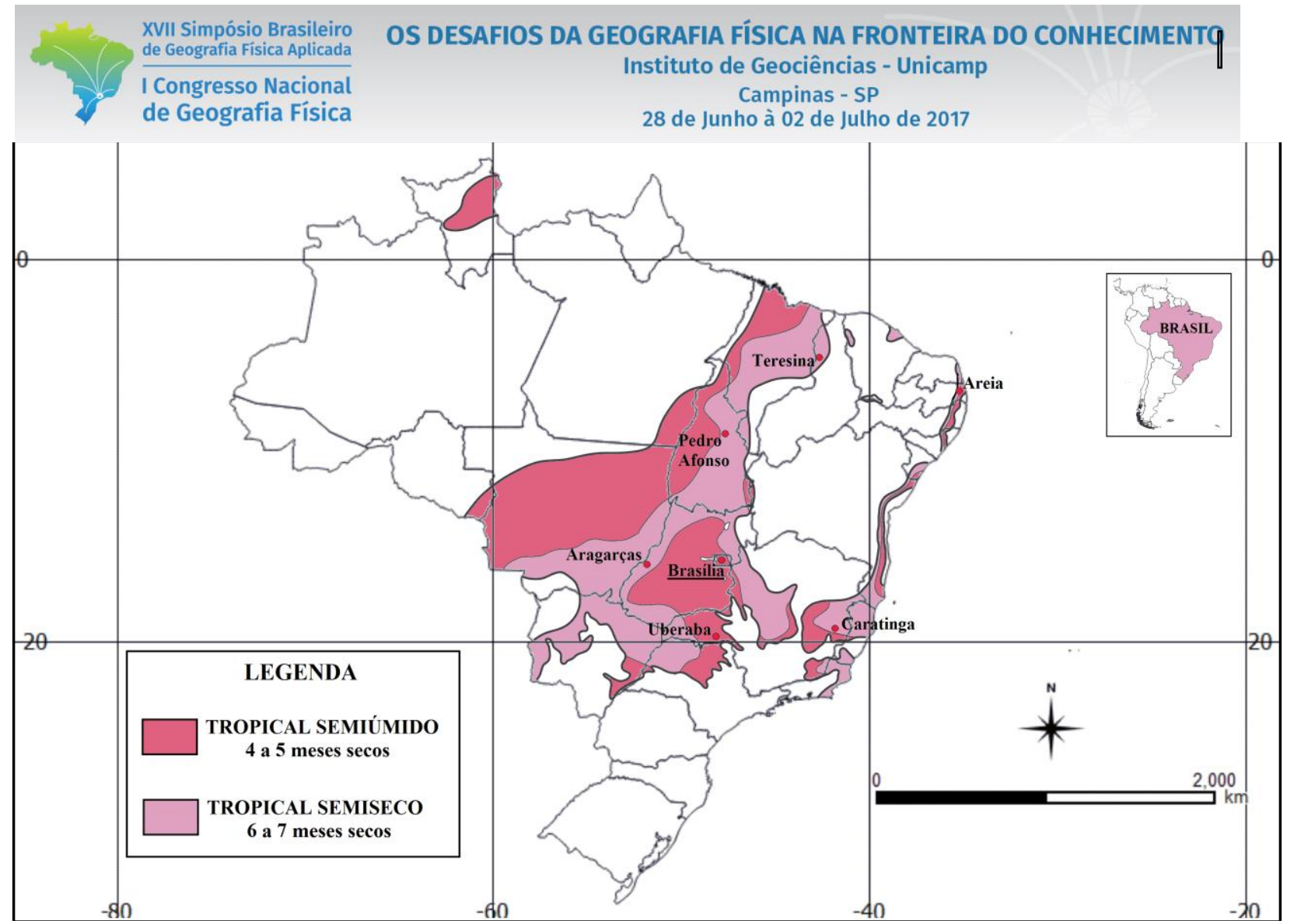

Figura 1 - Domínio climático tropical brasileiro subdividido em semiúmido/semiseco e estações do INMET utilizadas. Autor: NOVAIS, 2017.

Na figura 1 podemos observar a predominância de um tipo climático semiúmido no limite com regiões mais úmidas, como a Amazônia e o litoral leste nordestino. Esses limites foram comprovados pelos dados das estações que estão fora da análise, como as de Campina Grande-PB e Altamira-PA. Pela metodologia adotada, a primeira apresenta dez meses secos, sugerindo um clima semiárido. Já a segunda apresentou apenas dois meses secos, e pertence a um clima mais úmido. Uma segunda "mancha" semiúmida aparece nas áreas mais elevadas do centro do país e no extremo sul do domínio climático tropical, com influência na temperatura. A estação de Nhecolândia-MS foi a que serviu de delimitação para essa mancha na parte ocidental, mostrando que durante o ano, apenas dezembro e janeiro não são meses secos, portanto, também está inserido em um clima semiárido, o que é uma surpresa para a região do Pantanal Matogrossense.

O tipo semiseco ocupa uma faixa de transição entre o semiúmido da Amazônia e o semiúmido do centro-sul brasileiro, desde as cabeceiras do Pantanal passando pela planície do Araguaia, Tocantins, centro do Maranhão e alto vale do Parnaíba no Piauí. O tipo climático semiseco também vai desde o centro mineiro até o litoral capixaba, e segue para o norte fazendo a transição entre uma região seca (a oeste) e úmida (a leste). As serras de Ibiapaba e Araripe no Ceará, serra da Borborema na Paraíba, juntamente com a região de Fortaleza, entre a serra do Baturité e o oceano possuem condições 


\section{OS DESAFIOS DA GEOGRAFIA FÍSICA NA FRONTEIRA DO CONHECIMENTQ \\ Instituto de Geociências - Unicamp \\ Campinas - SP \\ 28 de Junho à 02 de Julho de 2017}

climáticas igualmente do tipo semiseco. Essas pequenas manchas foram delimitadas com o auxílio do mapa hipsométrico, já detalhado em metodologia.

Essa proposta de classificação climática difere da última utilizada pelo Instituto Brasileiro de Geografia e Estatística (IBGE) elaborada por Nimer (1972). Na classificação adotada pelo IBGE o clima megatérmico com 4 a 5 meses secos (equivalente ao tropical semiúmido) abrange uma área maior, e não existe um tipo semiseco, onde o clima semiárido já abrange os 6 meses secos. A metodologia utilizada por Nimer para considerar mês seco é a de Gaussen \& Bagnouls (1953), quando a precipitação pluviométrica mensal for menor que duas vezes o valor de sua temperatura média.

Com raríssimas exceções, em todo o domínio climático tropical domina as temperaturas elevadas. Por isso, a diferença entre as condições térmicas da primavera (sua estação mais quente) e do inverno (sua estação mais fria) é de pouca significância, tratando de condições médias.

A precipitação pluviométrica também segue o regime tropical, com dois períodos anuais, chuvas concentradas em uma época do ano, e um estação seca em outra época. As chuvas podem ocorrer tanto no verão (maior parte do domínio tropical) ou também no inverno (como é o caso das regiões próximas ao litoral nordestino). A estação seca ocorre na maior parte no inverno, mas também pode acontecer no verão (porção oriental do Nordeste).

A subdivisão do domínio tropical em dois tipos - semiúmido e semiseco - promove um melhor entendimento didático na diferenciação da quantidade de meses secos, aproximando esses tipos a domínios climáticos mais úmidos e mais secos. A metodologia é simples e de fácil identificação.

\section{Agradecimentos}

A Universidade Estadual de Goiás (UEG), instituição ao qual sou vinculado.

A Universidade Federal de Uberlândia (UFU), instituição onde curso o doutorado em geografia.

\section{Bibliografia}

BARRY, R.G.; CHORLEY, R.J. Atmosfera, tempo e clima. Porto Alegre: Bookman, 2013.

GAUSSEN, H.; BAGNOULS, F. Saison sèche et indice xérothermique. Soc. Hist. Nat. de Toulouse, França: Université de Toulouse, Facultei dês Sciences, 88. p. 193-240. 1953.

KÖPPEN, W. Das geographisca System der Klimate, in: Handbuch der Klimatologie, edited by: Köppen, W. and Geiger, G., 1. C. Gebr, Borntraeger, 1-44, 1936. 
MENDONÇA, F. DANNI-OLIVEIRA, I. M. Climatologia: noções básicas e climas do Brasil.São Paulo: Oficina de Textos, 2007.

NIMER, E. Climatologia do Brasil.Rio de Janeiro: IBGE, Departamento de Recursos Naturais e Estudos Ambientais. 1989.

NIMER, E. Ensaio de um novo método de classificação climática: contribuição à climatologia intertropical e subtropical, especialmente do Brasil. Boletim de Geografia. Rio de Janeiro, v. 31, n.277: pp.141-153, mar/abril, 1972.

NOVAIS, G.T. Mapa físico, político e rodoviário do Brasil: uma contribuição ao estudo da geografia nacional. Revista da Católica, Uberlândia, v. 4, n. 8, 2012.

QGIS Development Team, 2015.

ROLIM,G.S., SENTELHAS,P.C., BARBIERI, V. Planilhas no ambiente EXCEL TM para os cálculos de balanços hídricos: normal, sequencial, de cultura e de produtividade real e potencial. Revista Brasileira de Agrometeorologia, Santa Maria, v. 6, n.1, p133-137, 1998.

THORNTHWAITE, C. W.; MATHER, J.R. The water balance climatology.Centerion, v.8, nº. 1, pp.1-86.1955. WEBER, E.; HASENACK, H.; FERREIRA, C.J.S. Adaptação do modelo digital de elevação do SRTM para o sistema de referência oficial brasileiro e recorte por unidade da federação. UFRGS Centro de Ecologia. Porto Alegre, 2004. ISBN 978-85-63843-02-9. Disponível em http://www.ecologia.ufrgs.br/labgeo. Acesso em $02 / 01 / 2011$ 